\title{
Foreword: Professional Ethics in Business and Social Life
}

\author{
Mahmut Arslan \\ Alejo José G. Sison
}

There are many perspectives from which the reality of work can be viewed. As a mere occupation, it may be understood as an activity in which we engage during the greater part of our waking hours, apart from the time we spend attending to our biological needs. As employment, it seems to refer to some formal relationship or contract in which we agree to produce some goods or perform certain services in exchange for pay and other economic incentives. It could also be thought of as a career in which we compete against ourselves or our peers in an attempt to reach ever more lofty goals that provide us with great psychological satisfaction. But likewise, work may be conceived as a profession, as a personal response to a wider social calling, as an invitation to serve others. This has always been the dimension of work that has interested business ethics scholars and practitioners the most.

This special issue of the Journal of Business Ethics comprises selected papers from the 21st Annual Conference of the European Business Ethics Network (EBEN) held in Antalya, Turkey, 17-19 October, 2008. The Antalya conference was a memorable event, held in a well-known Mediterranean tourist destination. The theme of the conference was "Professional Ethics in Business and Social Life."

The present volume contains, in the first place, the invited keynote addresses of Joanne B. Ciulla, Heidi von Weltzien Hoivik, and Simon Robinson, delivered in their respective plenary sessions during the conference. Next come a series of studies concerning the legal and auditing professions, real estate agents, human resource and marketing managers, consumers, and public administrators. A couple of articles focusing on the moral learning and stakeholder perceptions of nongovernmental organizations (NGOs) follow. Finally, we offer some contributions on the use of "ethical hotlines" in transnational companies, Islamic work ethics in small and medium-sized enterprises (SMEs), and personalist ethics. The inclusion of articles written from the particular perspective of the conference's host network, Turkey, has been especially enriching.

As editors on behalf of the EBEN Executive Committee, we would like to thank the scholars who agreed to serve as anonymous reviewers for this special issue. We are particularly thankful to our local organizers, the Centre for Business Ethics and the Faculty of Economics of Hacettepe University, for their support and encouragement. Last but not least, we thank all participants who came to Antalya from all around the world and made the conference a success.

Mahmut Arslan Centre for Business Ethics, Hacettepe University, Beytepe, Ankara, Turkey E-mail:marslan@hacettepe.edu.tr

Alejo José G. Sison Department of Philosophy, University of Navarre, 31080 Pamplona, Spain E-mail: ajsison@unav.es

The EBEN European Business Ethics Network Special Issue from the 21st Annual Conference, Antalya, Turkey. 